Çukurova Üniversitesi Mühendislik Mimarlık Fakültesi Dergisi, 32(3), ss. 251-258, Eylül 2017

\title{
Kükürt ve Kül Giderimi Yapılmış Pirolitik Karbon Siyahı Katkılı MgO-C Refrakterlerin Mekanik Özelliklerinin İncelenmesi
}

\author{
Tuba BAHTLI ${ }^{*}$, Veysel Murat BOSTANCI ${ }^{2}$, Derya Yeşim HOPA ${ }^{3}$, \\ Şerife YALÇIN YASTI ${ }^{4}$
}

${ }^{1}$ Necmettin Erbakan Üniversitesi, Mühendislik ve Mimarlı Fakültesi, Metalurji ve Malzeme Mühendisliği Bölümü, Konya

${ }^{2}$ Necmettin Erbakan Üniversitesi, Fen Bilimleri Enstitüsü, Makine Mühendisliği, Konya

${ }^{3}$ Afyon Kocatepe Üniversitesi, Mühendislik Fakültesi, Kimya Mühendisliği Bölümü, Afyonkarahisar

${ }^{4}$ Selçuk Üniversitesi, Güzel Sanatlar Fakültesi, Seramik Bölümü, Konya

Geliş tarihi: 13.03.2017 Kabul tarihi: 25.08.2017

$\ddot{\mathbf{O z}}$

Lastik atıklarının refrakter sektöründe geri kazanımını sağlamak amacı ile yapılan bu çalışmada, piroliz reaktöründe $500{ }^{\circ} \mathrm{C}$ sıcaklık, $15{ }^{\circ} \mathrm{C} / \mathrm{dk}$ 1sıtma hızı ve $0,5 \mathrm{~L} / \mathrm{dk} \mathrm{N}_{2}$ akış hızı parametrelerinde elde edilen katı ürünün kükürt ve kül miktarları azaltılmış ve daha sonrasında $\mathrm{MgO}-\mathrm{C}$ refrakter malzemelerinin üretiminde karbon kaynağı olarak kullanılmıştır. Üretilen refrakterlerin yoğunluk, \% açık gözenek ve soğuk basma mukavemeti (SBM) değerlerinin kükürt ve kül miktarı ile değişimi incelenmiştir. Piroliz sonrası atık lastiğin ve kükürt ve kül giderimi sonrası elde edilen pirolitik karbon siyahı malzemelerinin X-Işını Difraktometresi (XRD) ile faz analizleri, taramalı elektron mikroskobu (SEM) ile mikroyapı analizleri ve Enerji Dağılımlı X-Işını Analizi (EDX) ile kimyasal analizleri gerçekleşmiştir. Kükürt ve kül miktarları azaldıkça, bu ürünlerin kullanıldığı refrakter malzemelerin \% açık gözenek miktarının ve yoğunluk değerlerinin yaklaşık aynı olmasına rağmen soğuk basma mukavemeti değerlerinin arttığı görülmüştür.

Anahtar Kelimeler: Piroliz, MgO-C, Refrakter, Soğuk basma mukavemeti

\section{Investigation of Mechanical Properties of MgO-C Refractories Produced by Pyrolytic Carbon Black with Removal of Sulfur and Ash}

\begin{abstract}
In this study, which aims recycling/regaining tire waste in the refractory sector, the amounts of sulfur and ash of the solid products obtained from the pyrolysis reactor at $500{ }^{\circ} \mathrm{C}, 15{ }^{\circ} \mathrm{C} / \mathrm{min}$ heating rate and $0.5 \mathrm{~L} / \mathrm{min} \mathrm{N}_{2}$ flow rate were reduced and then used in $\mathrm{MgO}-\mathrm{C}$ refractory materials as a carbon source. The exchange of density, \% open porosity and cold compressive strength (CCS) values with the amount
\end{abstract}

*Sorumlu yazar (Corresponding author): Tuba BAHTLI, taksoy@konya.edu.tr 
of sulfur and ash of the produced refractories were investigated. Phase analysis by X-ray diffractometry (XRD), microstructure analysis by scanning electron microscopy (SEM), and chemical analysis by energy diffraction X-Ray analysis (EDX) of pyrolytic carbon black materials obtained after waste tire pyrolysis and sulfur and ash removal were obtained. As the amounts of sulfur and ash decreased, the cold compressive strength values increased, although the open porosity and density values of the refractory materials used for these products were approximately the same.

Keywords: Pyrolysis, $\mathrm{MgO}-\mathrm{C}$, Refractory, Cold compressive strength

\section{GíRiș}

Magnezit karbon refrakterler, magnezya, pul grafit ve bağlayııı içeren karbon bağlı malzemelerdir ve kolay üretilirler. Üretim prosesi, karıştırma, presleme ve yaklaşık 200 C'de gerçekleştirilen temperlemeden ibarettir [1].

$\mathrm{Bu}$ iki ana bileşen (MgO ve grafit) oldukça değişik yapılara sahiptirler. Presleme işlemi sırasında grafit pulları deforme olup magnezya tanelerinin etrafını sararlar. $\mathrm{Bu}$ tip bir davranış, presleme kabiliyetinin artmasına ve dolayısıyla preslenen malzemedeki porozite miktarının azalmasına neden olur. Porozite miktarının azalması cüruf ve korozyon direncinin artması için önemli bir parametredir [1].

Ayrıca, MgO-C refrakterlerde kullanılan grafit ve $\mathrm{MgO}$ gibi refrakter oksitler, iyi termal şok direnci (grafitin düşük termal genleşme ve yüksek termal iletkenliği) ve mükemmel cüruf direnci (grafitin düşük 1slatılabilirliği) gibi değerli özellikler sağlar $[2,3]$.

Cürufa ve korozyona karşı direnci artırmak için kullanılan karbonun 3 türü bulunmaktadır. Bunlar:

- Bağlayıcı karbon: Bir katran veya reçinenin karbonlaştırılması sonucu ortaya çıkan karbon fazidir [4].

- Karbon siyahı

- Doğal grafittir [5].

Bu çalışmada, karbon kaynağı olarak kullanılan karbon siyahı atık lastiklerden piroliz işlemi sonucu elde edilmiştir. Her yıl Türkiye' de yaklaşık olarak 300.000 ton ömrünü tamamlamış lastik
(ÖTL) oluşmaktadır [6]. Çevreye de pek çok zararları olan atık lastiklerin geri kazanımları ile çevresel problemlerin önlenmesi ve aynı zamanda ekonomiye kazandırılması önem arz etmektedir. Atık lastiklerin sıvı, gaz ve katı ürünlere dönüşümünü mümkün k1lan piroliz yöntemiyle, atık lastiğin ağırlıkça yaklaşık \%40'lık bölümü katı ürüne dönüştürülmektedir. Geriye kalan \%60’lık bölümü sıvı ve gaz ürünlere dönüşmektedir [7].

Piroliz sırasında oluşan kükürt içerikli bileşiklerin yüksek termal dayanımı nedeniyle, kükürdün büyük bölümü katı ürün içerisinde yer almıştır [8].

Katı üründeki bir diğer problem olan yüksek kül içeriğinin büyük bölümünü, lastik üretim aşamasında vulkanizasyon işlemini hızlandırıcı olarak ilave edilen çinko oksit oluşturmaktadır [9].

Lastik pirolizi ile elde edilen pirolitik karbon siyahındaki kükürt ve kül miktarının azaltılması ile $\mathrm{MgO}-\mathrm{C}$ refrakterlerin mekanik özelliklerinin iyileşip iyileşmediği bu çalışma ile incelenmiş, kükürt ve kül miktarlarının azalması ile yoğunluk ve SBM değerlerinin arttı̆̆ı, \% açık gözenek değerlerinin ise azaldığı gözlenmiştir.

\section{MATERYAL VE METOT}

\subsection{Pirolitik Katı Ürün Kükürt ve Kül Giderimi}

Kullanılan atık lastik ince ve kalın olmak üzere iki tür tane boyutuna sahiptir. Kalın atık lastiğin elek analizi sonuçlarına göre; $0,850 \mathrm{~mm}<\mathrm{Dp}<1,6 \mathrm{~mm}$ aralığında tane boyutuna sahip olduğu 
görülmüsstür. İnce atık lastik ise $70 \mu \mathrm{m}<\mathrm{Dp}<850 \mu \mathrm{m}$ aralığında tane boyutuna sahiptir.

Afyon Kocatepe Üniversitesi Kimya Mühendisliği Bölümündeki reaktör ile lastik atığının pirolizinden $500^{\circ} \mathrm{C}$ sicaklik, $15{ }^{\circ} \mathrm{C} / \mathrm{dk}$ ssitma hizı ve $0,5 \mathrm{~L} / \mathrm{dk} \mathrm{N}_{2}$ akış hızında pirolitik katı elde edilmiştir.

Piroliz sonrası elde edilen bu katı ürüne öncelikle kükürt daha sonra kül giderimi işlemleri uygulanmıştır. Kükürt ve kül giderimleri için farklı tür ve konsantrasyonlardaki asitler kullanılarak ekstraksiyon işlemi uygulanmıştır.

Kükürt giderimini sağlayabilmek için 1 gr karbon siyahı başına $20 \mathrm{ml}$ 'lik $\% 37^{\prime}$ lik $\mathrm{HCl}$ ve $\% 65^{\prime}$ 'lik $\mathrm{HNO}_{3}$ asitlerinin 1:1 hacim oranında bir araya getirilmesiyle oluşturulan asit karışımı kullanılmıştır. 15 dakika boyunca $175{ }^{\circ} \mathrm{C}$ 'ye ayarlanmış etüvde 1 sıl işleme tabi tutulmuştur. Isıl işlem sırasında kükürt gaz halinde karbon siyahından uzaklaş̧ııılmışıı. Daha sonra, $1000 \mathrm{ml}$ kadar saf suyla, adi süzgeç kâğıdı kullanılarak süzme işlemi tamamlanmıştır. Süzme işleminin ardından karbon siyahı $100{ }^{\circ} \mathrm{C}$ 'ye ayarlanmış etüvde 24 saat boyunca kurutulmuştur.

Kükürt giderme işleminden sonra pirolitik karbon siyahının kül giderimi için iki aşamalı asitle ekstraksiyon işlemi uygulanmıştır:

Öncelikle 1 gr karbon siyahına $20 \mathrm{ml}$ asit karışımı ilave edilecek şekilde, kükürtü giderilmiş olan karbon siyah1 \%37'lik $\mathrm{HCl}$ ve \%65'lik $\mathrm{HNO}_{3}$ asitlerinin 1:1 hacim oranında karıştırılmasıyla oluşturulan asit karışımında $175{ }^{\circ} \mathrm{C}$ 'de etüvde 30 dakika boyunca 1 sıll işleme tabi tutulmuş, adi süzgeç kâğıdından süzülerek saf su ile yıkama işlemi gerçekleştirilmiş, son olarak $100{ }^{\circ} \mathrm{C}$ 'ye ayarlanmış etüvde 24 saat boyunca kurutulmuştur.

Sonrasında $1 \mathrm{~N} \mathrm{H}_{2} \mathrm{SO}_{4}$ ve $10 \mathrm{~N} \mathrm{NaOH}$ çözeltileri hacimce 1:1 oranında karıştırılarak bir karışım elde edilmiş̧ir. 1 gram pirolitik karbon siyahı ile $10 \mathrm{ml}$ karışım bir beherde bir araya getirerek 30 dakika boyunca $60{ }^{\circ} \mathrm{C}^{\prime}$ de etüvde 1 ssll işleme tabi tutulmuştur. Adi süzgeç kâğıdından süzme işleminden sonra süzgeç kâğıdı üzerindeki karbon siyahı $1500 \mathrm{ml}$ saf su ile yıkanmış, $100{ }^{\circ} \mathrm{C}$ 'ye ayarlanmış etüvde 24 saat boyunca kurutulmuştur.

\subsection{Kül ve Kükürt Giderim Sonrası Katı Ürün Analizleri}

- Kül analizi ağırlıkça yüzde olarak ASTM D 3174 test metoduna uygun olarak Afyon Kocatepe Üniversitesi Mühendislik Fakültesi Kimya Mühendisliği Bölümü Laboratuvarlarında gerçekleştirilmiştir.

- Kükürt miktarı ise Afyon Kocatepe Üniversitesi Teknoloji Uygulama ve Araştırma Merkezi'nde (TUAM) karbon-kükürt analiz cihazı (Met, Multilab) ile gerçekleştirilmiştir.

- Kül ve kükürt giderim işlemlerinden sonra karbon siyahı için: i) faz analizi Bruker/D8 Advance XRD (X-1şınları difraksiyonu) cihazında $\mathrm{Cu}_{\mathrm{K} \alpha}$ ş̧ınımı kullanılarak ve $10^{\circ}-100^{\circ}$ kırınım açısı aralığında gerçekleştirilmiş̧tir, ii) mikroyapı incelemesi ile Enerji Dağılımlı X-ışını (EDX) analizleri LEO 1430 VP model Taramalı Elektron Mikroskobu (SEM) cihazı ile Afyon Kocatepe Üniversitesi Teknoloji Uygulama ve Araştırma Merkezi'nde (TUAM) karakterize edilmiştir.

\section{3. Şekillendirme}

\%10 karbon içeren $\mathrm{MgO}$-karbon refrakter tuğla malzemesi olacak şekilde, ağ. \%50 (1-4) mm $\mathrm{MgO}, \% 30(0-1) \quad \mathrm{mm} \mathrm{MgO}$ ile \%10 (0-1) mm pirolitik kat1, $\% 10$ toz $(63 \mu \mathrm{m}$ altı $) \mathrm{MgO}$ hammaddeleri tartılmış, $\% 2$ toz novalak ve $\% 2$ sıv1 fenolik reçine ile karıştırılmış, Selçuk Üniversitesi Teknoloji Fakültesi laboratuvarında özel yapım pres ile $\sim 100 \mathrm{MPa}$ (35 bar) basınç uygulanarak $\sim 50 \mathrm{~mm}$ çapında ve $\sim 50 \mathrm{~mm}$ boyunda silindir şeklinde şekillendirilmiştir.

\subsection{Temperleme}

Şekillendirilen numuneler Selçuk Üniversitesi Güzel Sanatlar Fakültesi Seramik bölümündeki Nüve marka MF 120 model kül firını içerisinde 1.kademede $250 \quad{ }^{\circ} \mathrm{C}$ 'de 3 saat bekletilerek temperlenmiştir. Temperlemede $5{ }^{\circ} \mathrm{C} / \mathrm{dk}$ 'lık 1 sitma hızı kullanılmıştır. 


\subsection{Açık Gözenek ve Yoğunluk Ölçümü}

$\mathrm{Bu}$ çalışmada, farklı kompozisyonda hazırlanan parçalar 2'şer saat kaynatılmıştır. Böylece porlarda yer alan havanın çıkarılması ve porların su ile dolması sağlanmıştır. Daha sonra Archimedes düzeneği hazırlanmıştır ve numuneler düzeneğe yerleştirilerek hassas terazide tartılmıştır ve kaynatılan numunelerin su içerisindeki ağırlıkları belirlenmiştir $\left(\mathrm{W}_{\mathrm{b}}\right)$. Daha sonra sudan çıkarılan numunelerin yüzeyi kâğıt mendil ile silinerek yüzeylerindeki suyu alınıp, yaş ağırlıkları hassas terazi yardımıyla tespit edilmiştir $\left(\mathrm{W}_{\mathrm{c}}\right)$. Son aşama olarak parçalar etüvde kurutulduktan sonra, kuru ağırlıkları hassas terazide tartılarak belirlenmiştir $\left(\mathrm{W}_{\mathrm{a}}\right) . \quad \%$ görünen porozite ve bulk yoğunluk aşağıdaki eşitlikler kullanılarak hesaplanmıştır:

\% Görünen Porozite $=\left[\left(\mathrm{W}_{\mathrm{c}}-\mathrm{W}_{\mathrm{a}}\right) /\left(\mathrm{W}_{\mathrm{c}}-\mathrm{W}_{\mathrm{b}}\right)\right]^{* 100}$

Yığınsal (Bulk) Yoğunluk=[Wa/(Wc-Wb)]

\subsection{Mekanik Özelliklerin (Soğuk Basma Mukavemeti) Belirlenmesi}

Sekillendirilen numunelere Necmettin Erbakan Üniversitesi İnşaat Mühendisliği Bölüm
Laboratuvarında Liya marka basma test cihazı kullanılarak $4 \mathrm{kN} / \mathrm{sn}$ hızda 200 ton yük uygulanmıştır. Okunan basınç değerleri $(\mathrm{N})$; kesit alanına $\left(\mathrm{mm}^{2}\right)$ bölünerek mukavemet değeri $(\mathrm{MPa})$ hesaplanmıştır.

\section{ARAŞTIRMA BULGULARI}

Piroliz sonrası katı ürünün elek analizi yapılmıştır. Yapılan analiz sonuçlarında ince ürünün $70 \mu \mathrm{m}<\mathrm{Dp}<180 \mu \mathrm{m}$ aralığında tane boyutuna sahip olduğu, kalın ürünün ise $0,090 \mathrm{~mm}<\mathrm{Dp}<1,6 \mathrm{~mm}$ aralığında tane boyutuna sahip olduğu görülmüştür.

Piroliz sonrası katı ürüne uygulanan XRD analizi sonucu Şekil 1'de verilmiştir. Katı ürün içerisinde amorf yapida karbon, $\mathrm{Zn}_{1.9} \mathrm{In}_{0.1} \mathrm{O}_{1.76-\mathrm{x}} \mathrm{N}_{0.24}$ ile $\mathrm{ZnS}$ fazlarına ait pikler gözlenmiştir. Lastik üretiminde vulkanizasyon işlemini kontrol etmek için ilave edilen $\mathrm{ZnO}$, yine lastik üretiminde eklenen kükürt ile reaksiyona girerek $\mathrm{ZnS}$ oluşturmaktadır [8]. XRD sonuçlarına göre; piroliz işlemi sırasında ZnS kararlılığını koruyarak katı ürün içerisinde yer almaktadır.

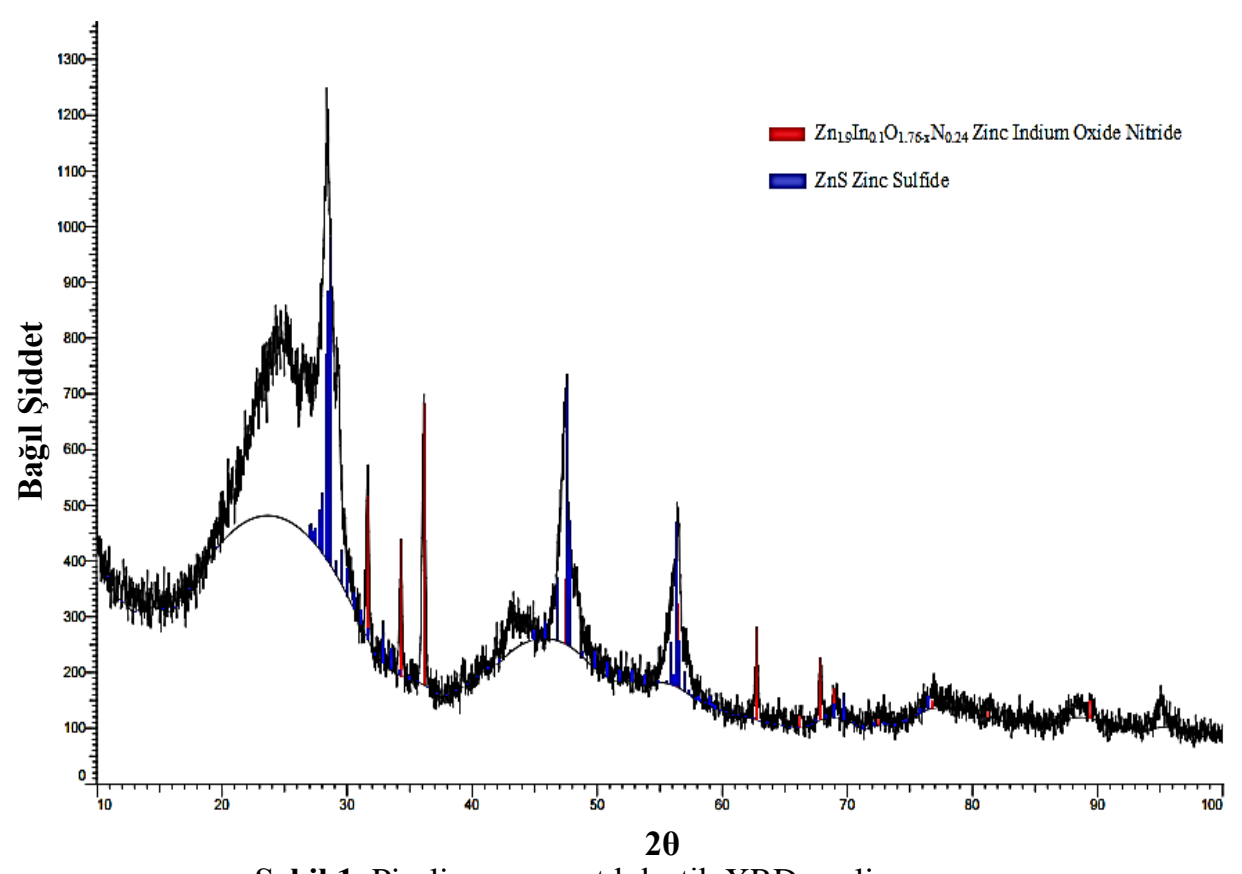

Şekil 1. Piroliz sonrası atık lastik XRD analiz sonucu 
Piroliz sonrası en düşük oranda kükürt içeren katı numunelere, kükürt oranını ve kül oranını daha da düşürmeye yönelik iyileştirme çalışmaları uygulanmıştır.

Piroliz reaktöründe $500{ }^{\circ} \mathrm{C}$ piroliz sıcaklığında, $15{ }^{\circ} \mathrm{C} / \mathrm{dk}$ 1sıtma hızında; $0,5 \mathrm{lt} / \mathrm{dk} \mathrm{N}_{2}$ akış hızında elde edilen D1: piroliz sonras1 iri karbon siyah1, D2: piroliz sonras1 ince karbon siyahı, D3: kükürt ve kül giderimi yapılarak iyileştirme yapılan iri karbon siyahı, D4: kükürt ve kül giderimi yapılarak iyileştirme yapılan ince karbon siyahı kullanılarak üretilen $\mathrm{MgO}-\mathrm{C}$ refrakterler için \% açık gözenek, yoğunluk, Soğuk Basma Mukavemeti (SBM) değerleri Çizelge 1'de verilmiştir.

Çizelge 1. Piroliz sonrası ve iyileştirme sonucu elde edilen karbon siyahı denemelerinin gözenek, yoğunluk ve Soğuk Basma Mukavemeti (SBM) sonuçları

\begin{tabular}{|l|c|c|c|c|}
\hline \multirow{2}{*}{ Numune Numaras1 } & \multicolumn{2}{|c|}{$\begin{array}{c}\text { Piroliz } \\
\text { Sonras1 }\end{array}$} & \multicolumn{2}{c|}{$\begin{array}{c}\text { İyileştirme } \\
\text { Sonras1 }\end{array}$} \\
\cline { 2 - 5 } & $\begin{array}{c}\text { D1 } \\
\text { (iri) }\end{array}$ & $\begin{array}{c}\text { D2 } \\
\text { (ince) }\end{array}$ & $\begin{array}{c}\text { D3 } \\
\text { (iri) }\end{array}$ & $\begin{array}{c}\text { D4 } \\
\text { (ince) }\end{array}$ \\
\hline Açı Gözenek \% & 11,85 & 9,69 & 13,79 & 13,34 \\
\hline $\begin{array}{l}\text { Arşimet Yoğunluğu } \\
\left.\text { (g/cm }{ }^{3}\right)\end{array}$ & 2,47 & 2,50 & 2,50 & 2,47 \\
\hline $\begin{array}{l}\text { Soğuk Basma Mukavemeti } \\
\text { (MPa) }\end{array}$ & 45,18 & 42,34 & 56,33 & 59,57 \\
\hline Kükürt Miktarı \% & 2,42 & 2,00 & 0,68 & 0,64 \\
\hline Kül Miktarı (\%) & 23 & 22 & 9,02 & 8,16 \\
\hline
\end{tabular}

Piroliz sonrası elde edilen karbon siyahının kullanıldığı $\mathrm{MgO}-\mathrm{C}$ refrakterler ile iyileștirme sonucu başka bir ifade ile kükürt ve kül giderimleri yapıldıktan sonra elde edilen karbon siyahının kullanıldığı MgO-C refrakterlerin yoğunluk ve \% açık gözenek değerleri birbirine yakın olmasına rağmen, kül ve kükürt uzaklaştığı için daha yüksek soğuk basma mukavemeti değerlerine ulaşılmıştır.

İyileştirme sonrası (kükürt giderimi ve ardından iki aşamalı kül giderimi) katı ürünün kükürt miktarına bağlı açık gözenek, yoğunluk ve soğuk basma mukavemeti grafikleri ile kül giderim sonrası kül miktarına bağlı \% açık gözenek, yoğunluk ve soğuk basma mukavemeti grafikleri sirası ile Şekil 2 ve Şekil 3'de verilmiştir.
Kükürt ve kül miktarları azaldıkça, bu ürünlerin kullanıldığı refrakter malzemelerin \% açık gözenek miktarının ve yoğunluk değerlerinin yaklaşık aynı olmasına rağmen Soğuk Basma Mukavemeti değerlerinin arttığı görülmüştür.

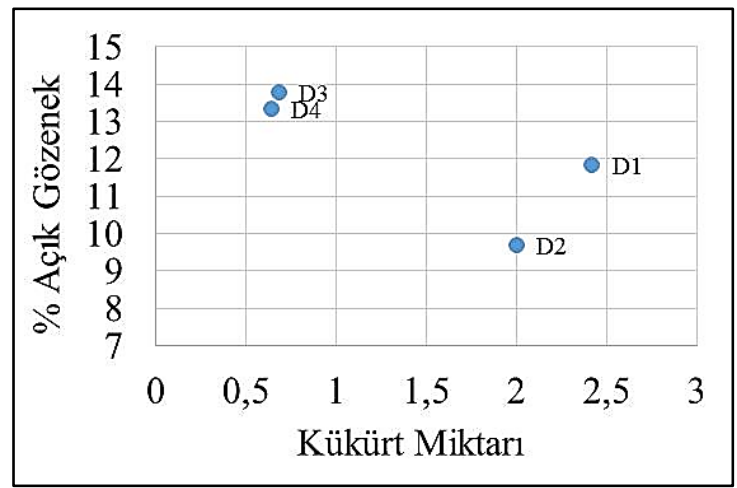

(a)

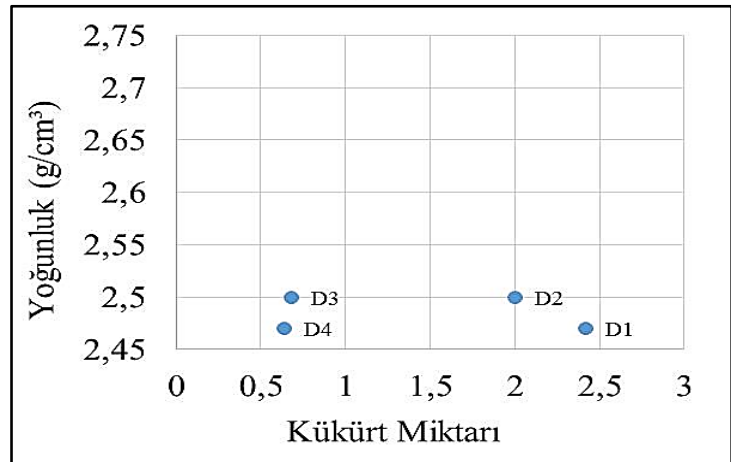

(b)

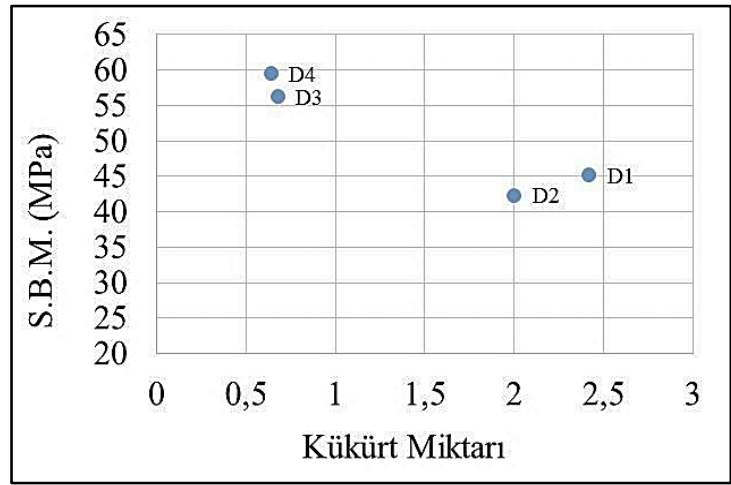

(c)

Şekil 2. Kükürt miktarı en düsük olan katı ürün için iyileştirme öncesi ve sonrası, a) \% Açık gözenek b) Yoğunluk ve c) Soğuk Basma Mukavemeti (SBM) grafikleri 


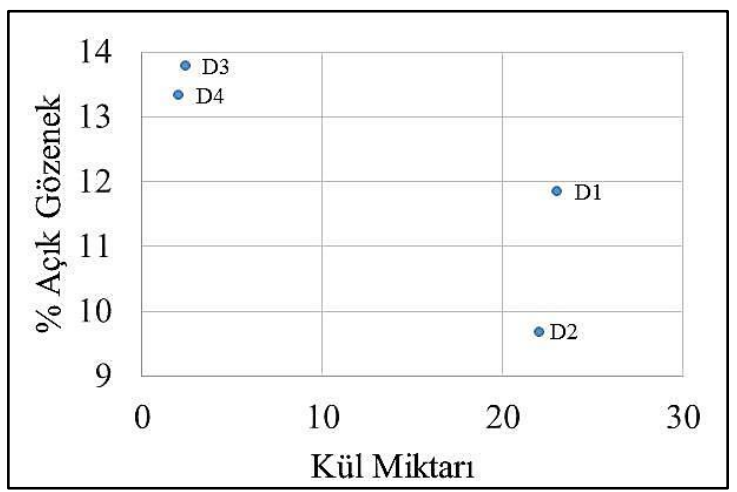

(a)

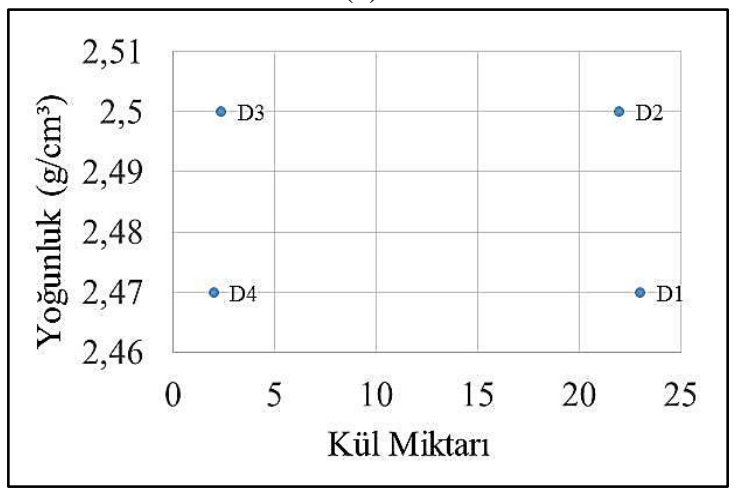

(b)

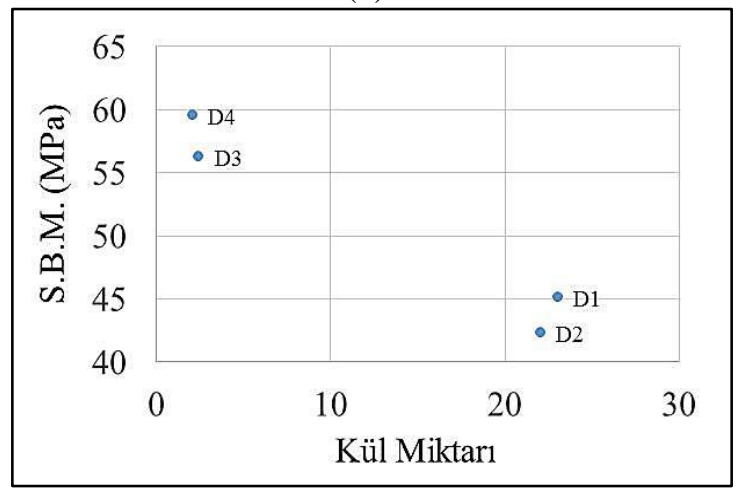

(c)

Şekil 3. Kükürt miktarı en düşük olan katı ürün için iyileştirme öncesi ve sonrası, kül miktarına bağlı a) \% Açık gözenek, b) Yoğunluk ve c) Soğuk Basma Mukavemeti (SBM) grafikleri

Pirolitik Karbon Siyahına uygulanan kükürt ve kül giderim işlemlerinin ardından elde edilen son ürünün içerdiği inorganik madde miktarının yüksek oranda düşürülmüş olduğu XRD sonucunda görülmektedir. Pirolitik Karbon Siyahına ait kırınım paterni Şekil 4'de sunulmuştur. Pirolitik Karbon Siyahı büyük ölçüde amorf yap1 sergilemektedir.

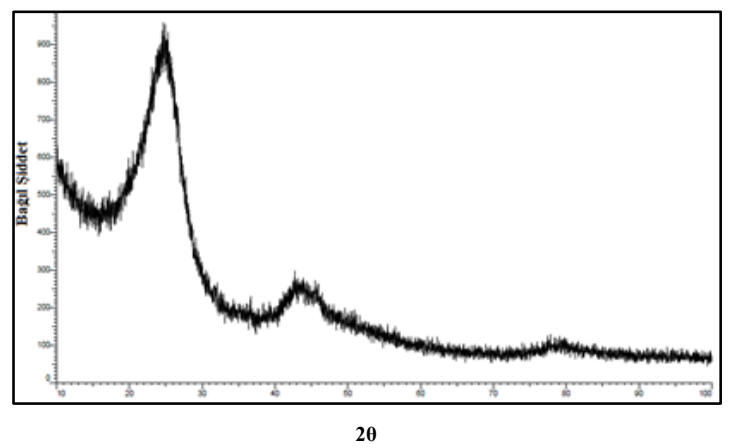

Şekil 4. İyileştirme sonrası (Kükürt ve kül giderimi sonrası) pirolitik karbon siyahı XRD paterni

Piroliz ile üretilen pirolitik karbon siyahının ve yıkanarak kükürt ve kül oranı azaltılan pirolitik karbon siyahlarının morfolojik özelliklerini kıyaslamak amacıyla taramalı elektron mikroskobu (SEM) görüntüleri alınmıştır. Ayrıca, her karbon siyahının içermekte olduğu elementlerin türlerini tespit etmek amacıyla EDX (Enerji Yayınımlı XIşınları) analizi uygulanmıştır. SEM-EDX sonuçları Şekil 5'de ve Çizelge 2'de sunulmuştur.

Şekil 5'de yer alan taramalı elektron mikroskobu görüntüleri, Pirolitik karbon siyahının sahip olduğu pürüzlü yüzey özellikleri ile geniş bir yüzey alanına sahip olarak görünmektedir. Geniş yüzey alanı karbon siyahında istenilen bir özelliktir. Geniş yüzey alanı sayesinde yapı ile etkin bir şekilde bütünleşerek mukavemeti artırabilmektedir. Çizelge 2'de yer alan EDX sonuçlarına bakıldığında, kükürt ve kül giderim işlemleri ile yapıdaki kükürt ve inorganik maddelerin uzaklaştırılması sonucunda karbon miktarının yüzde içerisinde arttığı görülmüştür. Yıkama işlemleriyle, kükürt miktarında belirgin şekilde azalma görülmüştür. Asidik ortamda çözünür olan ZnS katı üründen uzaklaştırılmıştır. Böylelikle, kül miktarının önemli bir bölümünü oluşturan çinko yapıdan uzaklaştırılmıştır. 


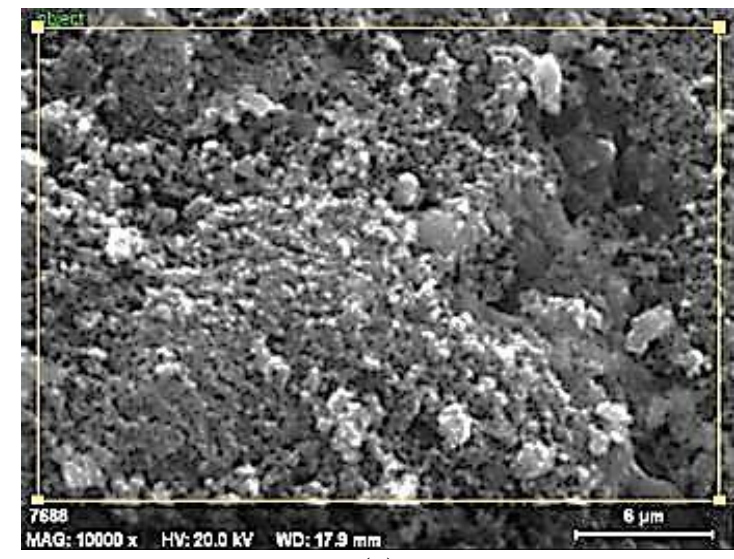

(a)

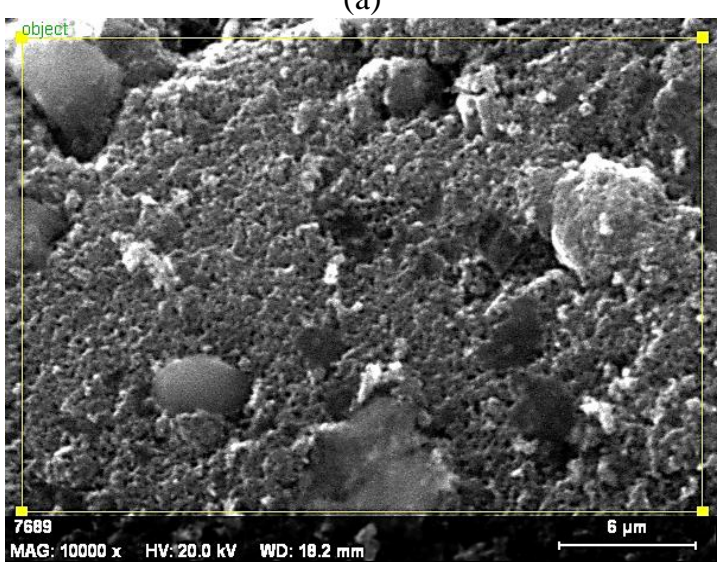

(b)

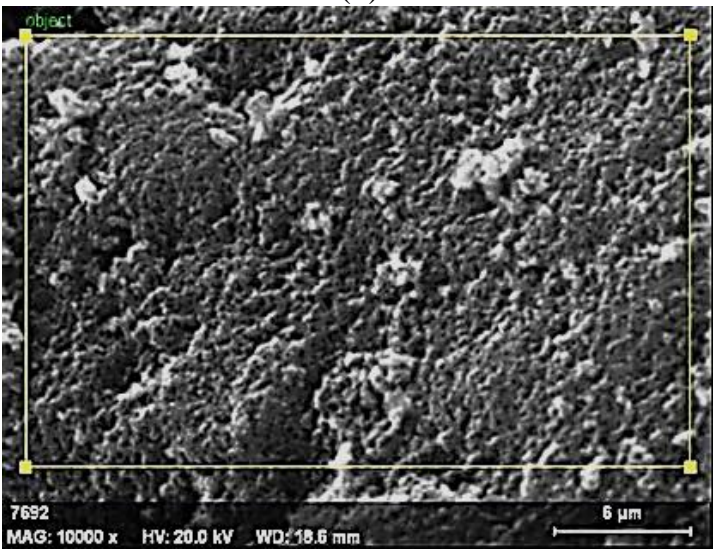

(c)

Şekil 5. Taramalı elektron mikroskobu görüntüleri: a) Piroliz sonrası karbon siyahı, b) Kükürt giderimi sonrası karbon siyahı, c) Kül giderimi sonrası karbon siyahı
Çizelge 2. Piroliz sonrası karbon siyahı, kükürt giderimi sonrası karbon siyahı ve kül giderimi sonrası karbon siyahı EDX analiz sonuçları

\begin{tabular}{|c|c|c|c|}
\hline Element & $\begin{array}{c}\text { Piroliz } \\
\text { sonras1 } \\
\text { karbon } \\
\text { siyahı }\end{array}$ & $\begin{array}{l}\text { Kükürt } \\
\text { giderimi } \\
\text { sonrası } \\
\text { karbon } \\
\text { siyahı }\end{array}$ & $\begin{array}{c}\text { Kül } \\
\text { giderimi } \\
\text { sonrası } \\
\text { karbon } \\
\text { siyahı }\end{array}$ \\
\hline & A ̆̆g. $\%$ & A ̆g. $\%$ & Ăg. $\%$ \\
\hline Karbon & 42,82 & 49,76 & 69,97 \\
\hline Oksijen & 14,75 & 35,13 & 21,16 \\
\hline Alüminyum & 0,73 & 0,87 & - \\
\hline Silisyum & 1,69 & 10,48 & 1,01 \\
\hline Kükürt & 13,06 & 0,71 & 1,37 \\
\hline Demir & 1,05 & - & - \\
\hline Çinko & 25,91 & - & - \\
\hline Klor & - & 3,04 & 3,27 \\
\hline Sodyum & - & - & 3,23 \\
\hline
\end{tabular}

\section{TARTIŞMA VE SONUÇLAR}

Yapılan çalışma ile pirolitik karbon siyahı içerisindeki kükürt ve kül miktarlarının MgO-C refrakterlerin \% açık gözenek miktarı, yoğunluk ve Soğuk Basma Mukavemeti değerleri için önemli etkisi olduğu belirlenmiştir. Kükürt ve kül miktarlarının azalması ile yoğunluk ve SBM değerlerinin arttığı, \% açık gözenek değerlerinin ise azaldığ 1 gözlenmiştir. En iyi sonuçlar iki kez yıkanarak kükürt ve kül miktarları azaltılan pirolitik karbon siyahı kullanımında elde edilmiştir. Piroliz sonrası elde edilen karbon siyahının kullanıldığı $\mathrm{MgO}-\mathrm{C}$ refrakterlere göre yoğunluk ve açık gözenek değerleri birbirine yakın olmasına rağmen, iri taneli iyileştirilmiş pirolitik karbon siyahı ile üretilen $\mathrm{MgO}-\mathrm{C}$ refrakterlerin Soğuk Basma Mukavemeti (SBM) değerlerinde iyileştirilmemiş iri taneli karbon siyahı içeren $\mathrm{MgO}-\mathrm{C}$ refraktere göre yaklaşı 1 1,25; ince taneli iyileştirilmiş pirolitik karbon siyahı ile üretilen $\mathrm{MgO}-\mathrm{C}$ refrakterlerin Soğuk Basma Mukavemeti (SBM) değerlerinde iyileştirilmemiş ince taneli 
Kükürt ve Kül Giderimi Yapılmış Pirolitik Karbon Siyahı Katkılı MgO-C Refrakterlerin Mekanik Özelliklerinin Incelenmesi

karbon siyahı içeren $\mathrm{MgO}-\mathrm{C}$ refraktere göre yaklaşık 1,45 kat iyileşme gözlenmiştir.

\section{TEŞEKKÜR}

$\mathrm{Bu}$ çalışma 115M371 numaralı Tübitak projesi tarafindan desteklenmiştir.

\section{KAYNAKLAR}

1. Gökçe, A.S., 2003. Antioksidan Katkıların Magnezya-karbon Refrakterin Oksidasyon Davranışına Etkisi, Yüksek Lisans Tezi, ITTÜ Fen Bilimleri Enstitüsü, İstanbul.

2. Faghihi, M.A., Sani, A.Y., 2002. Oxidation Kinetics of $\mathrm{MgO}-\mathrm{C}$ Refractory Bricks, Ceramics International, 28, 835-839.

3. Zhang, S., Lee, W.E., 2001. Influence of Additives on Corrosion Resistance and Corroded Microstructures of $\mathrm{MgO}-\mathrm{C}$ Refractories, Journal of the European Ceramic Society, 21, 2393-2405.

4. Sodyum Hegza Metafosfat Reçine ve Zift Gibi Bağlayıcıların Refraktere Kazandırdığı Özellikler, muhendislik.istanbul.edu.tr/ metalurji/wp-content/.../Sodyum-hegzametafosfat.pptx sitesinden alınmıştır.

5. DPT, 2001. Taş ve Toprağa Dayalı Ürünler Sanayii Özel İhtisas Komisyonu Raporu (DPT: 2551 - ÖİK: 567). Sekizinci Beş Yıllık Kalkınma Planı, 2551, 19, http://ekutup.dpt.gov.tr/imalatsa/tastopra/oik56 7.pdf sitesinden alınmıştır.

6. http://www.lasder.org.tr/otl-2/otl/ (Son erişim tarihi: 02/06/2017).

7. Martinez, J.D., Puy, N., Murillo, R., Garcia T., Navarro, M., N., Mastral A.M., 2013. Waste Tyre Pyrolysis-a Review, Renewable and Sustainable Energy Reviews, 23,179-213.

8. Hu, H., Fang, Y., Liu, H., Yu, R., Luo, G., Liu, W., Li, A., Yao, H., 2014. The Fate of Sülfür During Rapid Pyrolysis of Scrap Tires, Chemosphere, 97:102-7.

9. Bernardo, M., Lapa, N., Gonçalves, M., Mendes, B., Pinto, F., 2012. Study of the Organic Extraction and Acidic Leaching of Chars Obtained in the Pyrolysis of Plastics,
Tire Rubber and Forestry Biomass Wastes, Procedia Engineering, 42, 1739-1746. 